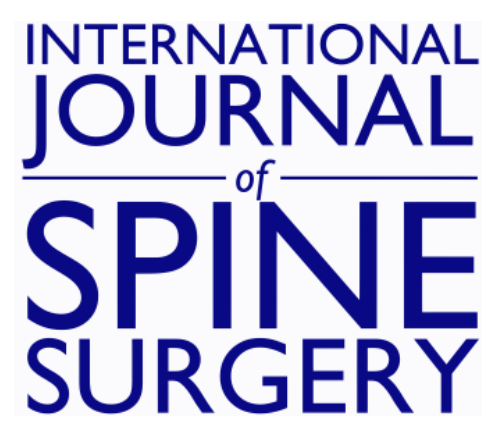

\title{
The Perioperative Symptom Severity of Higher Patient Health Questionnaire-9 Scores Between Genders in Single-Level Lumbar Fusion
}

James M. Parrish, Nathaniel W. Jenkins, Dustin H. Massel, Augustus J. Rush III, Manasi S. Parrish, Nadia M. Hrynewycz, Thomas S. Brundage, Rebecca Van Horn and Kern Singh

Int J Spine Surg 2021, 15 (1) 62-73

doi: https://doi.org/10.14444/8007

http://ijssurgery.com/content/15/1/62

This information is current as of April 26, 2023.

Email Alerts Receive free email-alerts when new articles cite this article. Sign up at:

http://ijssurgery.com/alerts

The International Journal of Spine Surgery

2397 Waterbury Circle, Suite 1,

Aurora, IL 60504, Phone: +1-630-375-1432 


\title{
The Perioperative Symptom Severity of Higher Patient Health Questionnaire-9 Scores Between Genders in Single- Level Lumbar Fusion
}

\author{
JAMES M. PARRISH, MPH, ${ }^{1}$ NATHANIEL W. JENKINS, MS ${ }^{1}$ DUSTIN H. MASSEL, $M D,{ }^{2}$ AUGUSTUS J. \\ RUSH III, MD,${ }^{2}$ MANASI S. PARRISH, MPH,${ }^{3}$ NADIA M. HRYNEWYCZ, BS, ${ }^{1}$ THOMAS S. BRUNDAGE, \\ BS, ${ }^{1}$ REBECCA VAN HORN, MD, ${ }^{3}$ KERN SINGH, MD ${ }^{1}$ \\ ${ }^{I}$ Department of Orthopaedic Surgery, Rush University Medical Center, Chicago, Illinois, ${ }^{2}$ Department of Orthopaedics, Miller School of Medicine, University of \\ Miami, Miami, Florida, ${ }^{3}$ Road Home Program, Department of Psychiatry, Rush University Medical Center, Chicago, Illinois
}

\begin{abstract}
Background: Preoperative depression is associated with increased perioperative pain, worse physical function, reduced quality of life, and inferior outcomes. Few studies have evaluated depressive symptoms between genders for individuals undergoing minimally invasive transforaminal lumbar interbody fusion (MIS TLIF). The purpose of this investigation was to assess the severity of Patient Health Questionnaire-9 (PHQ-9) scores among patients with depressive symptoms before and after single-level MIS TLIF.

Methods: A prospective surgical registry was retrospectively reviewed for spine surgeries between March 2016 and December 2018. We included patients with at least mild depressive symptoms (PHQ-9 scores $\geq 5$ ) who underwent primary, single-level MIS TLIF and compared genders using $\chi^{2}$ tests and $t$ tests. Genders were stratified by depressive symptom severity: mild (5-9), moderate (10-14), and moderately severe $(\geq 15)$ and then analyzed at preoperative and postoperative intervals: 6 weeks, 12 weeks, 6 months, and 1 year. Finally, PHQ-9 scores were validated with a Pearson correlation test against the 12-item Short Form (SF-12) Mental Composite Score (MCS) and the Veterans RAND (VR12) MCS.

Results: Of 75 subjects, $44.0 \%$ were women and the mean age was 49.9 years. The preoperative distribution among PHQ-9 subgroups was $38.7 \%, 26.6 \%$, and $34.7 \%$ for mild, moderate, and moderately severe depressive symptoms, respectively. Among PHQ-9 stratifications both genders demonstrated intermittent statistically significant improvements in PHQ-9 scores. The moderately severe PHQ-9 subgroup had improvement at all postoperative time points. The PHQ-9 scores demonstrated a strong correlation with the SF-12 MCS and VR-12 MCS at all postoperative evaluations.

Conclusion: At baseline and by the final 1-year follow-up there were no statistically significant PHQ-9 score differences between genders within any depressive symptom stratifications. Whereas some contend that men and women have substantial mental health differences, this study is aligned with growing evidence that demonstrates similar depressive symptoms between genders.
\end{abstract}

Level of Evidence: 3.

Clinical Relevance: Men and women may be at an equivalent risk for perioperative depressive symptoms.

Lumbar Spine

Keywords: lumbar interbody fusion, major depressive disorder, TLIF, Patient Health Questionaire-9, PHQ-9, spine, sex, Transforaminal, Short Form-12, SF-12, Veterans RAND-12, VR-12

\section{INTRODUCTION}

The number of spine surgeries in the United States continues to rise, but the precise rate of spine surgery varies widely and has been associated with individual spine surgeon surgical criteria as well as local practice trends. ${ }^{1-4}$ This expansion in surgicalprocedure volume has been accompanied by increased complication rates and costs, as compared with more conservative interventions. ${ }^{1,4}$ To min- imize surgical morbidity and unnecessary costs, more research is needed on how to optimize spine surgery candidates to receive the most functional improvement while minimizing risk of complications. ${ }^{1}$

Anxiety and depressive symptoms are observed in one-third of patients with chronic back pain who undergo spine surgery. ${ }^{8-10}$ Overall, patients who experience chronic back pain are up to 3 times more 
likely than the general population to experience depressive symptoms. This indicates that mental health symptoms are a significant cause of morbidity among those considering elective spine surgery. ${ }^{10-13}$ Studies have also demonstrated that preoperative depression and anxiety are significant predictors of preoperative and postoperative pain and worse physical function and are correlated with worse surgical outcomes and recovery. ${ }^{10,13-17}$

To better understand the complex relationship between depressive symptoms and chronic back pain, a recent systematic review identified 5 broad categories of associations between mental health and spine surgery. ${ }^{10}$ The authors determined that associations between mental health and spine surgery were primarily tied to (1) pain, (2) patient desire for more information (specifically about what to expect after surgery), ${ }^{18}$ (3) poor physical ability (worse levels of disability), (4) issues related to employment (with unemployed patients having higher rates of depression), ${ }^{10,19,20}$ and (5) preexisting psychological disturbances. $^{10}$

Numerous studies have observed that preoperative anxiety and depression predict surgical outcomes. ${ }^{14-17}$ Among patients experiencing depression prior to surgery, correlations have been identified with negative outcomes after surgery, such as poor physical ability, $1,15,16,21-23$ increased pain, ${ }^{1,15,23-25}$ decreased satisfaction, ${ }^{21}$ and decreased quality of life. ${ }^{1,22,26}$ Depression screening is often accomplished using the 9-item Patient Health Questionnaire (PHQ-9), which is a survey based on the Diagnostic and Statistical Manual of Mental Disorders (Fourth Edition; DSM-IV). The PHQ-9 is a questionnaire that includes 9 questions that are scored on a scale of $0-3$ depending on frequency of symptoms, with a maximum score of 27 . Increased scores indicate greater depressive symptoms, and scores can be grouped into the following categories $^{27}$ : (1) minimal depression: 0-4, (2) mild depression: 5-9, (3) moderate depression: 10-14, (4) moderately severe depression: 15-19 and (5) severe depression: 20-27. In the general population, depression is more common in women than men. ${ }^{28}$ Some have reported that there is little gender difference in levels of depression during preoperative evaluations. ${ }^{29}$ Few studies have evaluated gender differences in preoperative and postoperative depressive symptoms in patients undergoing minimally invasive transforaminal lumbar interbody fusion (MIS TLIF). The purpose of this study was to assess gender differences with regard to depression, measured by PHQ-9, in patients before and after MIS TLIF.

\section{METHODS}

\section{Study Cohort}

Following approval from our institutional review board (ORA No. 14051301), a prospective surgical registry was retrospectively reviewed for spine surgeries between March 2016 and December 2018. Patients were included if they had at least mild depressive symptoms (PHQ-9 scores $\geq 5$ ) before undergoing elective primary, single-level MIS TLIF for degenerative spine pathologies. The following patients were excluded from analysis: those who did not complete a preoperative PHQ-9 survey and those whose surgeries were indicated for trauma, infection, or malignancy. Though patients underwent surgery in both an inpatient hospital and in an ambulatory care center, all patients were treated by 1 surgeon at both surgical centers, which were affiliated with a single academic institution.

\section{Demographics and Outcome Measures}

Baseline and demographic characteristic observations were recorded as variables for each patient. Demographic observations included participant age, body mass index (BMI) classification $\left(<30 \mathrm{~kg} / \mathrm{m}^{2}\right.$ or $\geq 30 \mathrm{~kg} / \mathrm{m}^{2}$ ), American Society of Anesthesiology physical classification (ASA), Charlson Comorbidity Index (CCI), preoperative chronic health comorbidities, ethnicity, gender, and smoking status. Characteristics observed during the perioperative time period included operative time duration, intraoperative estimated blood loss, length of hospital stay (hours), surgical setting (inpatient or ambulatory surgical center), postoperative discharge day, and daily postoperative narcotic consumption (oral morphine equivalents). Patient-reported outcome (PRO) surveys collected included the PHQ-9, Short Form-12 Mental Health Composite Scale (SF-12 MCS) and Veterans RAND-12 Mental Health Composite Scale (VR-12 MCS) scores. Patients completed these surveys preoperatively and during postoperative evaluations at 6 weeks, 12 weeks, 6 months, and 1 year.

The PHQ-9, derived from the $D S M-I V$, is a questionnaire of 9 questions used to assist clinicians in identifying patients who are more likely to experience depression. The questions ask patients 
how often they have had depressive symptoms in the past 2 weeks, using a scale of $0-3$ for each question $(0=$ not at all $; 1=$ several days; $2=$ more than half the days, 3 =nearly every day). The maximum score is 27, with higher scores indicating an increased likelihood of depressive symptoms. ${ }^{1,27,30}$

The SF-12 and VR-12 are other commonly used PRO measures that evaluate overall patient health. The SF-12 MCS is scored from 0-100, with a better mental health status reflected in a higher numerical score. ${ }^{31}$ The VR-36 survey has a short-form subset of questions known as the VR-12. The VR-12 survey assesses potential limitations placed on functioning in association with challenges surrounding energy, pain, mental health, and social health. The VR-12 survey is standardized with a $t$ score metric. The mean VR-12 score is 50 with a standard deviation of $10 .^{31}$ The VR-12 has been widely validated in numerous investigations. ${ }^{32}$

\section{Statistical Analysis}

Patient groups were categorized by gender and stratified by baseline PHQ-9 depressive symptom severity category including 5-9 (mild), 10-14 (moderate), and 15 or greater (moderately severe or greater). ${ }^{27}$ The relationship of gender with other demographic variables such as baseline PHQ-9 score, smoking status, medical diagnosis, BMI, and ethnicity were analyzed using a $\chi^{2}$ test. Perioperative characteristics, PHQ-9 outcome scores, and postoperative improvement scores were stratified by depressive-symptom category. A Student $t$ test analyzed continuous variables including age at time of operation, preoperative PHQ-9, and CCI. Statistical tests ( $t$ test or $\chi^{2}$ ) were used to compare perioperative attributes among the gender subgroups, including operative time (from first incision to skin closure), estimated blood loss, length of stay, surgical setting, discharge day, and daily postoperative narcotic consumption. A $t$ test was also used to assess possible gender differences in postoperative PHQ-9 score improvement at all preoperative and postoperative assessments. A paired $t$ test assessed differences between preoperative score at each postoperative time point. Mean $\Delta$ values (i.e., the score difference in preoperative PHQ-9 score and postoperative score) were compared at each time point by gender subgroup. Finally, a Pearson correlation coefficient analysis with SF-12 and VR-12 was used to assess the validity of our findings. Correlations were interpret- ed using $r$ values with $.1 \leq|r|<.3$ assessed as a weak correlation; $.3 \leq|r|<.5$ reflecting a moderate correlation, and $|r| \geq .5$ indicating a strong correlation. ${ }^{33}$

\section{RESULTS}

\section{Demographic and Perioperative Variables}

Our cohort of 75 single-level MIS TLIF patients was $44.0 \%$ women, with a mean age of $49.9 \pm 10.8$ years. Of the participants, $58.7 \%$ were obese (BMI $\geq 30 \mathrm{~kg} / \mathrm{m}^{2}$; Table 1), $87.8 \%$ were nonsmokers, and $72.7 \%$ were white. There were no statistically significant ethnicity differences between genders. The average CCI for the cohort was 0.9 . The 3 most frequent comorbidities in the cohort were hypertension $(29.7 \%)$, arthritis $(17.6 \%)$, and diabetes $(16.2 \%)$. When stratifying by PHQ-9 score subgroup, we found that $38.7 \%$ had mild depressive symptoms (PHQ-9 score of 5-9), 26.6\% had moderate depressive symptoms (PHQ-9 score of $10-14$ ), and $34.7 \%$ had moderately severe depressive symptoms (PHQ-9 score of $\geq 15$ ). Overall, there were no statistically significant differences between genders for any demographic (Table 1) or perioperative variables (Table 2).

\section{PHQ-9 Outcomes and Validation}

There were no statistically significant differences among mean PHQ-9 scores for men and women within either the mild (PHQ-9 score of 5-9) or moderate (PHQ-9 score of 10-14) depressive symptom stratifications (Table 3 ). The moderately severe depressive symptom stratification (PHQ-9 score of $\geq 15$ ) had transient differences in mean PHQ-9 scores at 12 weeks $(P=$ $.039)$ and 6 months $(P=.038)$. At 1 year, there were no statistically significant mean PHQ-9 score differences between genders for any of the 3 stratifications.

Within the mild depressive symptom stratification, women had significant improvement at 6 months $(P=.003)$ and 1 year $(P=.009)$ when compared with their preoperative scores. Within the moderate depressive symptom stratification, women had significant score improvement at 6 weeks $(P=$ $.031)$, and men had significant improvement at 6 weeks $(P<.001), 12$ weeks $(P=.006)$, and 6 months $(P=.001)$. Within the moderately severe depressive symptom stratification, both men and women had 
Table 1. Patient demographics by gender.

\begin{tabular}{|c|c|c|c|c|}
\hline & Total, \% (n) & Female & Male & $P$ Value ${ }^{\mathrm{a}}$ \\
\hline Total & $100.0(75)$ & $44.0(33)$ & $56.0(42)$ & \\
\hline Age, mean $\pm \mathrm{SD}, \mathrm{y}$ & $49.9 \pm 10.8$ & $52.1 \pm 9.9$ & $48.1 \pm 11.2$ & .368 \\
\hline \multicolumn{4}{|l|}{ PHQ-9 score group, \% (n) } & .761 \\
\hline Mild (5-9) & $38.7(29)$ & $42.4(14)$ & $35.7(15)$ & \\
\hline Moderate $(10-14)$ & $26.6(20)$ & $27.3(9)$ & $26.2(11)$ & \\
\hline Moderately severe $(\geq 15)$ & $34.7(26)$ & $30.3(10)$ & $38.1(16)$ & \\
\hline \multicolumn{4}{|l|}{ Body mass index, $\%(\mathrm{n})$} & .521 \\
\hline$<30 \mathrm{~kg} / \mathrm{m}^{2}$ & $41.3(31)$ & $45.5(15)$ & $38.1(16)$ & \\
\hline$\geq 30 \mathrm{~kg} / \mathrm{m}^{2}$ & $58.7(44)$ & $54.5(18)$ & $61.9(26)$ & \\
\hline \multicolumn{4}{|l|}{ Smoking status, \% (n) } & .480 \\
\hline Nonsmoker & $87.8(65)$ & $84.9(28)$ & $90.2(37)$ & \\
\hline Smoker & $12.2(9)$ & $15.2(5)$ & $9.8(4)$ & \\
\hline \multicolumn{4}{|l|}{ Ethnicity, \% (n) } & .800 \\
\hline African American & $9.5(7)$ & $9.1(3)$ & $9.8(4)$ & \\
\hline Asian & $2.7(2)$ & $3.0(1)$ & $2.4(1)$ & \\
\hline Hispanic & $14.9(11)$ & $9.1(3)$ & $19.5(8)$ & \\
\hline White & $67.6(50)$ & $72.7(24)$ & $63.4(26)$ & \\
\hline Other & $5.4(4)$ & $6.1(2)$ & $4.9(2)$ & \\
\hline \multicolumn{4}{|l|}{ ASA Score, \% (n) } & .864 \\
\hline 1 & $17.1(12)$ & $16.7(5)$ & $17.5(7)$ & \\
\hline 2 & $60.0(42)$ & $63.3(19)$ & $57.5(23)$ & \\
\hline$\geq 3$ & $22.9(16)$ & $20.0(6)$ & $25.0(10)$ & \\
\hline Charlson Comorbidity Index & $0.9 \pm 1.1$ & $1.1 \pm 1.2$ & $0.9 \pm 0.9$ & .399 \\
\hline \multicolumn{5}{|c|}{ Preoperative medical diagnosis, $\%(n)^{\mathrm{b}}$} \\
\hline Hypertension & $29.7(22)$ & $18.2(6)$ & $39.0(16)$ & .051 \\
\hline Arthritis & $17.6(13)$ & $27.3(9)$ & $9.8(4)$ & .050 \\
\hline Diabetes & $16.2(12)$ & $18.2(6)$ & $14.6(6)$ & .681 \\
\hline Metastasis & $0.5(3)$ & $0.6(1)$ & $0.5(2)$ & .916 \\
\hline Myocardial infarction & $2.7(2)$ & $0.0(0)$ & $4.9(2)$ & .198 \\
\hline AIDS & $0.2(1)$ & $0.0(0)$ & $0.3(1)$ & .507 \\
\hline Neurologic disease & $0.2(1)$ & $0.0(0)$ & $0.3(1)$ & .507 \\
\hline Congestive heart failure & $1.3(1)$ & $0.0(0)$ & $2.4(1)$ & .372 \\
\hline Renal failure & $1.3(1)$ & $0.0(0)$ & $2.4(1)$ & .372 \\
\hline
\end{tabular}

Abbreviations: ASA, American Society of Anesthesiologists; CCI, Charlson Comorbidity Index; PHQ-9, Patient Health Questionnaire-9.

${ }^{a} P$ value was calculated using the Student $t$ test (continuous), $\chi^{2}$ (categorical), or Fisher exact test (categorical).

${ }^{\mathrm{b}}$ There were no patients in our study with a recorded medical history of AIDS, paraplegia, congestive heart failure, peripheral vascular disease, metastatic disease, liver disease, chronic obstructive pulmonary disease, or gastrointestinal bleeds.

statistically significant improvement (Figure 1) at all postoperative time points $(P \leq .021$, all).

When evaluating gender subgroups for preoperative and postoperative $\Delta$ values, individuals with mild depressive symptoms demonstrated a significant difference in improvement at the 6month follow-up $(P=.031$; Table 4). For individuals with moderate depressive symptoms, there were no significant differences between genders at any time point. Those within the moderately severe depressive symptom stratification had significant differences in improvement at the 12-week $(P=.010)$ and 6 -month $(P=.034)$ follow-ups. Finally, PHQ-9 scores were validated against SF-12 MCS and VR-12 MCS, graphing each time point on a scatterplot (Figures 2-6). A Pearson's correlation coefficient test at each time point demonstrated that PHQ-9 scores had a strong correlation with both SF-12 MCS and VR-12 MCS scores (Table 5).

\section{DISCUSSION}

\section{Background and Gender Similarities}

Spine surgery rates within the United States continue to rise, ${ }^{34}$ and it is now estimated that an annual 900000 Americans undergo spinal procedures. ${ }^{35}$ Although international spine surgery rate assessments are currently lacking, several investigators have asserted concerns that the cost of spine surgery is significantly higher in the United States than in other developed countries. ${ }^{36,37}$ Depression is also more common among patients undergoing decompression or fusion in the United States than in other countries. ${ }^{38}$ In the United States, depression rates have rapidly increased within the past decade. ${ }^{39}$ Whereas elevated rates of depression have been highlighted among various demographic groups, women typically experience depression at 2 to 3 times the rate of men. Though this difference has been observed in numerous settings, our study 
TLIF PHQ-9 Between Genders

Table 2. Operative characteristics by gender and PHQ-9 score stratification.

\begin{tabular}{|c|c|c|c|}
\hline & Female & Male & $P$ Value $^{a}$ \\
\hline Total, \% (n) & $44.0(33)$ & $56.0(42)$ & \\
\hline \multicolumn{4}{|c|}{ Mild PHQ-9 scores (5-9), mean \pm SD } \\
\hline Operative time, $\min ^{\mathrm{b}}$ & $117.6 \pm 25.0$ & $120.5 \pm 29.3$ & .773 \\
\hline Estimated blood loss, $\mathrm{mL}$ & $64.3 \pm 112.1$ & $41.4 \pm 20.3$ & .460 \\
\hline Length of hospital stay, $\mathrm{h}$ & $24.2 \pm 13.7$ & $27.1 \pm 22.3$ & 679 \\
\hline Surgical setting, $\%(\mathrm{n})$ & & & .742 \\
\hline Inpatient hospital & $78.6(11)$ & $73.3(11)$ & \\
\hline Ambulatory surgical center & $21.4(3)$ & $26.7(4)$ & \\
\hline Discharge day, \% (n) & & & .991 \\
\hline POD 0 & $21.43(3)$ & $26.67(4)$ & \\
\hline POD 1 & $50(7)$ & 46.67 (7) & \\
\hline POD 2 & $21.43(3)$ & $20(3)$ & \\
\hline POD 3 & $7.14(1)$ & $6.67(1)$ & \\
\hline \multicolumn{4}{|c|}{ Daily narcotic consumption by $\mathrm{POD}$, mean $\pm \mathrm{SD}$} \\
\hline POD 0 (OME) & $56.2 \pm 27.5$ & $48.5 \pm 23.6$ & .425 \\
\hline POD 1 (OME) & $37.0 \pm 27.0$ & $29.8 \pm 32.6$ & .528 \\
\hline POD 2 (OME) & $45.0 \pm 21.2$ & $43.8 \pm 28.1$ & .959 \\
\hline POD 3 (OME) & $\ldots{ }^{c}$ & $\ldots$ & $\ldots$ \\
\hline \multicolumn{4}{|c|}{ Moderate PHQ-9 Scores $(10-14)$, mean \pm SD } \\
\hline Operative time, $\min ^{\mathrm{b}}$ & $118.8 \pm 51.0$ & $140.3 \pm 29.8$ & .255 \\
\hline Estimated blood loss, $\mathrm{mL}$ & $72.2 \pm 80.5$ & $34.1 \pm 12.6$ & .137 \\
\hline Length of hospital stay, $\mathrm{h}$ & $26.6 \pm 11.4$ & $30.6 \pm 25.1$ & .682 \\
\hline Surgical setting, $\%(\mathrm{n})$ & & & .742 \\
\hline Inpatient hospital & $88.9 \%(8)$ & $63.6(7)$ & \\
\hline Ambulatory surgical center & $11.1 \%(1)$ & $36.4(4)$ & \\
\hline Discharge day, \% (n) & & & 0.285 \\
\hline POD 0 & $22.2(2)$ & $36.4(4)$ & \\
\hline POD 1 & $66.7(6)$ & $27.3(3)$ & \\
\hline POD 2 & $11.1(1)$ & $27.3(3)$ & \\
\hline POD 3 & $0.0(0)$ & $9.1(1)$ & \\
\hline \multicolumn{4}{|c|}{ Daily narcotic consumption by POD, mean \pm SD } \\
\hline POD 0 (OME) & $65.3 \pm 23.2$ & $43.4 \pm 24.2$ & .064 \\
\hline POD 1 (OME) & $35.8 \pm 24.5$ & $31.8 \pm 33.3$ & .767 \\
\hline POD 2 (OME) & $30.0 \pm 0.0$ & $56.7 \pm 5.8$ & .057 \\
\hline POD 3 (OME) & $\ldots$ & $\ldots$ & $\ldots$ \\
\hline \multicolumn{4}{|c|}{ Moderately severe PHQ-9 scores $(\geq 15)$, mean \pm SD } \\
\hline Operative time, $\min ^{\mathrm{b}}$ & $100.4 \pm 54.3$ & $126.9 \pm 22.6$ & .094 \\
\hline Estimated blood loss, $\mathrm{mL}$ & $47.5 \pm 36.2$ & $50.3 \pm 33.9$ & .843 \\
\hline Length of hospital stay, $\mathrm{h}$ & $36.6 \pm 23.1$ & $29.6 \pm 27.4$ & .540 \\
\hline Surgical setting, $\%(\mathrm{n})$ & & & .946 \\
\hline Inpatient hospital & $70.0(7)$ & $68.8(11)$ & \\
\hline Ambulatory surgical center & $30.0(3)$ & $31.3(5)$ & \\
\hline Discharge day, $\%(\mathrm{n})$ & & & .213 \\
\hline POD 0 & $30.0(3)$ & $31.3(5)$ & \\
\hline POD 1 & $20.0(2)$ & $50.0(8)$ & \\
\hline POD 2 & $40.0(4)$ & $6.3(1)$ & \\
\hline$>$ POD 3 & $10.0(1)$ & $12.5(2)$ & \\
\hline \multicolumn{4}{|c|}{ Daily narcotic consumption by POD, mean \pm SD } \\
\hline POD 0 (OME) & $64.7 \pm 35.6$ & $62.4 \pm 33.7$ & .880 \\
\hline POD 1 (OME) & $46.8 \pm 49.1$ & $41.9 \pm 36.7$ & .777 \\
\hline POD 2 (OME) & $52.5 \pm 40.5$ & $48.8 \pm 15.9$ & .908 \\
\hline POD 3 (OME) & $30.0 \pm 0.0$ & $37.5 \pm 31.8$ & .879 \\
\hline
\end{tabular}

Abbreviations: OME, oral morphine equivalents; PHQ-9, Patient Health Questionnaire-9; POD, postoperative day.

${ }^{\text {a }} P$ value was calculated using Student $t$ test (continuous), $\chi^{2}$ analysis (categorical), or Fisher exact test.

${ }^{\mathrm{b}}$ Operative time was measured from skin incision to skin closure.

${ }^{\mathrm{c}}$ Ellipses indicate insufficient observations for mean and significance assessment.

found no significant gender difference that persisted over time among depressive symptom stratifications.

Our cohort had a slightly lower percentage of women than men ( $44 \%$ vs $56 \%$, respectively). The cohort in our investigation falls within the range of other studies ${ }^{40-42}$ involving minimally invasive spine surgery that have reported female cohort compositions ranging from $43 \%-48 \%$. In observing no statistically significant difference between gender PHQ-9 scores in the preoperative setting, our study is aligned with at least 2 other studies ${ }^{29,43}$ that investigated preoperative mental health status comparisons among both genders. Despite the supposed and widely asserted increased lifetime prevalence of depression among women, one possible reason for equality of preoperative depressive symptoms could be the similar experiences of all surgical candidates 
Parrish et al.

Table 3. Mean PHQ-9 scores by gender subgroup and depressive symptom score stratification. Time period stratified by PHQ-9 score.

\begin{tabular}{|c|c|c|c|c|c|}
\hline & Female, Mean \pm SD $(n)^{a}$ & $P$ Value $^{\mathrm{b}}$ & Male, Mean \pm SD $(n)$ & $P$ Value $^{\mathrm{b}}$ & $P$ Value $^{\mathrm{c}}$ \\
\hline \multicolumn{6}{|c|}{ Mild PHQ-9 scores (5-9) } \\
\hline Preoperative & $6.09 \pm 1.22(11)$ & & $6.45 \pm 1.13(11)$ & & .890 \\
\hline $6 \mathrm{wk}$ & $6.18 \pm 4.85(11)$ & .951 & $8.18 \pm 4.49(11)$ & .252 & .368 \\
\hline $12 \mathrm{wk}$ & $4.38 \pm 3.54(8)$ & .386 & $6.00 \pm 3.65(10)$ & .716 & .363 \\
\hline $6 \mathrm{mo}$ & $2.80 \pm 3.08(10)$ & .003 & $6.50 \pm 4.38(12)$ & .782 & .221 \\
\hline $1 \mathrm{y}$ & $2.00 \pm 2.24(7)$ & .009 & $7.14 \pm 5.43(7)$ & .751 & .567 \\
\hline \multicolumn{6}{|c|}{ Moderate PHQ-9 scores (10-14) } \\
\hline Preoperative & $11.43 \pm 1.13(7)$ & & $12.33 \pm 1.66(9)$ & & .379 \\
\hline $6 \mathrm{wk}$ & $6.14 \pm 4.30(7)$ & .031 & $6.56 \pm 3.17(9)$ & $<.001$ & .828 \\
\hline $12 \mathrm{wk}$ & $7.00 \pm 5.73(6)$ & .095 & $4.83 \pm 3.06(6)$ & .006 & .433 \\
\hline $6 \mathrm{mo}$ & $5.20 \pm 6.38(5)$ & .118 & $4.00 \pm 4.90(7)$ & .001 & .719 \\
\hline $1 \mathrm{y}$ & $7.50 \pm 8.35(4)$ & .466 & $5.00 \pm 5.00(2)$ & .500 & .738 \\
\hline \multicolumn{6}{|c|}{ Moderately severe PHQ-9 scores $(\geq 15)$} \\
\hline Preoperative & $19.50 \pm 2.73(8)$ & $\ldots$ & $19.46 \pm 3.07(13)$ & ... & .820 \\
\hline $6 \mathrm{wk}$ & $10.00 \pm 8.80(8)$ & .016 & $12.38 \pm 7.08$ & .001 & .502 \\
\hline $12 \mathrm{wk}$ & $6.43 \pm 3.60(7)$ & $<.001$ & $12.30 \pm 6.11(10)$ & $<.001$ & .039 \\
\hline $6 \mathrm{mo}$ & $5.88 \pm 3.80(8)$ & $<.001$ & $10.90 \pm 5.28(10)$ & .002 & .038 \\
\hline $1 \mathrm{y}$ & $7.00 \pm 2.94(4)$ & .003 & $5.25 \pm 4.57(4)$ & .021 & .544 \\
\hline
\end{tabular}

Abbreviations: PHQ-9, Patient Health Questionnaire-9.

${ }^{\mathrm{a}}(\mathrm{n})$ indicates the number of patients that could be used for paired $t$ test calculations. Values in boldface indicate statistical significance.

${ }^{\mathrm{b}} P$ value was calculated using paired t-test (continuous) to compare each time point score to the preoperative value.

${ }^{\mathrm{c}} P$ value was calculated using Student's t-test (continuous) to compare subgroup scores at each time point.

during a presurgical work-up. In the presurgical environment, regardless of gender, every patient faces a litany of agreements, disclosures, release forms, and waivers. It has been hypothesized that during this time, patients might perceive the potential mortality risk associated with surgical procedures. This perception has been associated with feelings of physical constraint, fear, anxiety, and depression. If the presurgical experience for patients of either gender is similar, then it is understandable that potential triggers for a depressive mental status might exist for both genders, and that particularly among individuals who are predisposed to psychiatric disorders, each gender might experience similar levels of depression. This might account for the equity we observed when compared with differences that exist in the general population.

\section{Moderately Severe Depressive Symptoms}

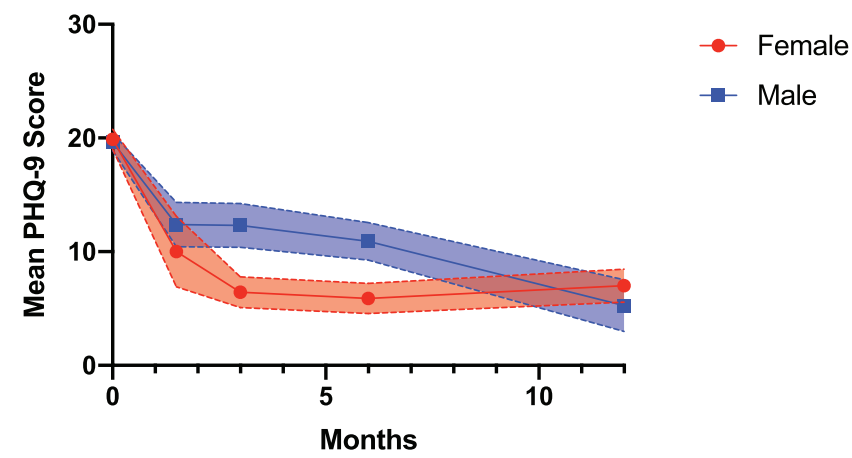

Figure 1. Mean Patient Health Questionnaire-9 (PHQ-9) scores over time by gender within the moderately severe $\mathrm{PHQ}-9$ score stratification (preoperative PHQ-9 score $\geq 15$ ).
If preoperative anxiety were the only factor at play, however, we might expect differences among the genders to increase during the postoperative recovery time period.

Our results, however, indicate a lack of gender difference that persists through the final follow-up. Among the mild and moderate PHQ-9 scorestratified subgroups, there were no differences in mean PHQ-9 scores between genders at any of the evaluations through 1 year. Within the moderately severe stratification, men did have increased mean PHQ-9 scores at the 12-week and 6-month evaluations, but there was no mean score difference at 1 year. This lack of statistically significant differences between genders, with regard to postoperative mental status, is aligned with the findings of at least one other study, ${ }^{44}$ which investigated postoperative mental states within 14 postoperative days. Possible explanations for our observed persistent mental status equivalence is a foray into the various methods for diagnosing major depressive disorder. For example, although it is asserted that women carry more than twice the lifetime risk of experiencing depressive symptoms, there is a long history of studies that indicate undiagnosed depression is substantially more frequent among men than women. ${ }^{4-48}$ Complicating these observations, men are identified as much less likely to seek mental health assistance. ${ }^{49}$ Even when comparing women with the same standardized diagnostic instruments, women are nonetheless diagnosed with major depressive disorder more often than men. Previous 
TLIF PHQ-9 Between Genders

Table 4. Preoperative to postoperative PHQ-9 score differences $(\Delta)$ by gender subgroup and depressive symptom score stratification.

\begin{tabular}{|c|c|c|c|}
\hline Time Period Stratified by PHQ-9 Score & Female, Mean \pm SD $(\mathbf{n})^{\mathrm{a}}$ & Male, Mean \pm SD (n) & $P$ Value $^{\text {b }}$ \\
\hline \multicolumn{4}{|l|}{ Mild PHQ-9 scores (5-9) } \\
\hline \multicolumn{4}{|l|}{ Preoperative } \\
\hline $6 \mathrm{wk}$ & $-0.09 \pm 4.81(11)$ & $-1.73 \pm 4.71(11)$ & .430 \\
\hline $12 \mathrm{wk}$ & $1.13 \pm 3.44(8)$ & $0.40 \pm 3.37(10)$ & .659 \\
\hline $6 \mathrm{mo}$ & $3.10 \pm 2.47(10)$ & $-0.33 \pm 4.08(12)$ & .031 \\
\hline $1 \mathrm{y}$ & $3.86 \pm 2.67(7)$ & $-0.71 \pm 5.68(7)$ & .078 \\
\hline \multicolumn{4}{|l|}{ Moderate PHQ-9 scores (10-14) } \\
\hline \multicolumn{4}{|l|}{ Preoperative } \\
\hline $6 \mathrm{wk}$ & $5.29 \pm 4.99(7)$ & $5.78 \pm 2.86(9)$ & .807 \\
\hline $12 \mathrm{wk}$ & $5.00 \pm 5.97(6)$ & $6.50 \pm 3.45(6)$ & .606 \\
\hline $6 \mathrm{mo}$ & $6.40 \pm 7.20(5)$ & $8.29 \pm 3.77(7)$ & .565 \\
\hline $1 \mathrm{y}$ & $3.75 \pm 9.00(4)$ & $5.00 \pm 5.00(2)$ & .874 \\
\hline \multicolumn{4}{|l|}{ Moderately severe PHQ-9 scores $(\geq 15)$} \\
\hline \multicolumn{4}{|l|}{ Preoperative } \\
\hline $6 \mathrm{wk}$ & $9.50 \pm 8.54(8)$ & $7.08 \pm 5.88(13)$ & .449 \\
\hline $12 \mathrm{wk}$ & $13.43 \pm 3.46(7)$ & $6.80 \pm 5.12(10)$ & .010 \\
\hline $6 \mathrm{mo}$ & $14.50 \pm 3.55(8)$ & $8.60 \pm 6.43(10)$ & .034 \\
\hline $1 \mathrm{y}$ & $13.75 \pm 2.99(4)$ & $14.50 \pm 6.45(4)$ & .840 \\
\hline
\end{tabular}

Abbreviation: PHQ-9, Patient Health Questionnaire-9.

a (n) indicates the number of patients who could be used for paired $t$ test calculations because they had paired preoperative and postoperative values for the given time point. Values in boldface indicate statistical significance.

${ }^{\mathrm{b}} P$ Value was calculated using a Student $t$ test (continuous) to compare subgroup scores at each time point.

research has demonstrated that women are also more likely to develop depression and anxiety after lumbar spine surgery. ${ }^{50}$ Such findings could imply that some clinicians may have an unconscious gender bias in diagnostic depression evaluations. ${ }^{51}$ In addition to the lack of gender difference at the vast majority of observed time points, both genders displayed multiple statistically significant improvements.

Overall, each gender achieved statistically significant improvement at 7 of the paired comparisons (Table 3). Four of these observed improvements occurred among the most severe depressive symptom $(\geq 15)$ stratification. Other studies assessing postoperative changes have also observed decreases

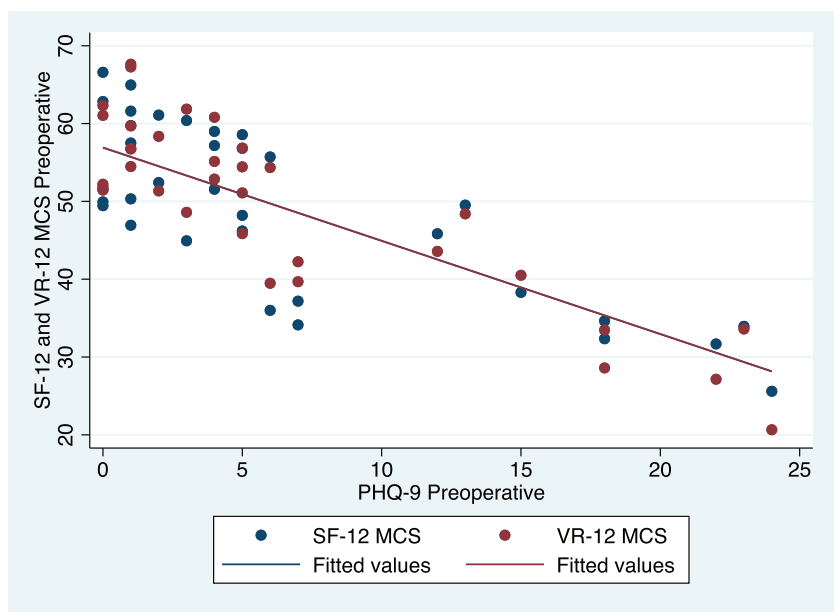

Figure 2. Patient Health Questionnaire-9 (PHQ-9) correlation scatterplot with Short Form-12 (SF-12) and Veterans RAND-12 (VR-12) MCS at the preoperative time point. in depressive symptoms after surgical intervention. ${ }^{52}$ In addition, our results suggest that patients with greater severity of preoperative depressive symptoms experienced a larger improvement in PHQ-9 scores through the 1-year follow-up. Although other investigators $^{53}$ have also linked increased levels of preoperative depressive symptoms to larger magnitudes of postoperative improvement, our study adds to this literature with our finding that improvement among those with more severe PHQ-9 scores $(\geq 15)$ is nearly equivalent among both genders.

When comparing the average $\Delta$ value from the preoperative to postoperative PHQ-9 evaluation, significantly different improvements were observed within the mild depressive symptom stratification at 6 months. Within the moderately severe PHQ-9 score stratification, significant differences in improvement occurred at 12 weeks and 6 months. At the 1-year postoperative time point, there were no statistically significant differences in the magnitude of improvement between genders. There are varied perspectives on whether substantial differences in mental states actually exist between genders. ${ }^{54} \mathrm{~A}$ lack of gender difference has been observed with mental states such as fear, anxiety, and depression in the perioperative environment $t^{43}$ and among postoperative mental improvements. ${ }^{44}$

The relevance of our findings that both genders share a potentially equivalent risk of similar preoperative and postoperative PHQ-9 scores further emphasizes the importance of adequately screening all patients seeking possible surgical 


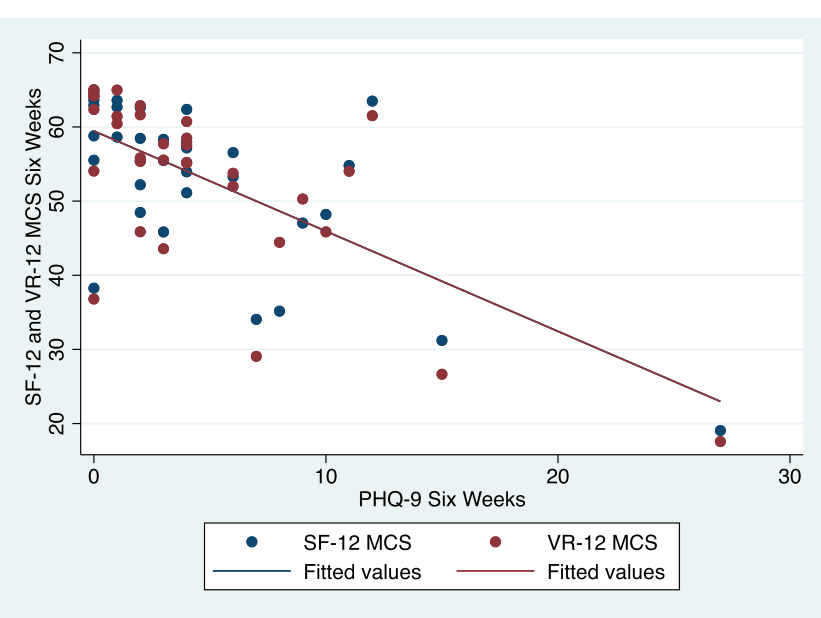

Figure 3. Patient Health Questionnaire-9 (PHQ-9) correlation scatterplot with Short Form-12 (SF-12) and Veterans RAND-12 (VR-12 MCS) at the 6-week time point.

intervention. Whereas numerous studies have investigated the relationship between low preoperative mental health scores and an increased risk for adverse events, ${ }^{55}$ complications, mortality, ${ }^{56}$ narcotic use,${ }^{55}$ higher levels of pain, ${ }^{57-59}$ higher levels of opioid consumption, ${ }^{59}$ and worsened postoperative outcomes, there is a scarcity of literature investigating perioperative depressive symptoms between genders. Our stratified analysis of perioperative characteristics revealed no significant difference between genders. Whereas there was no significant difference between genders with regard to surgical setting (i.e., those who underwent surgery in an inpatient hospital vs in an ambulatory surgical center), it may nonetheless be an important consideration with regard to mental health. Among appropriately selected patients, outpatient minimal-

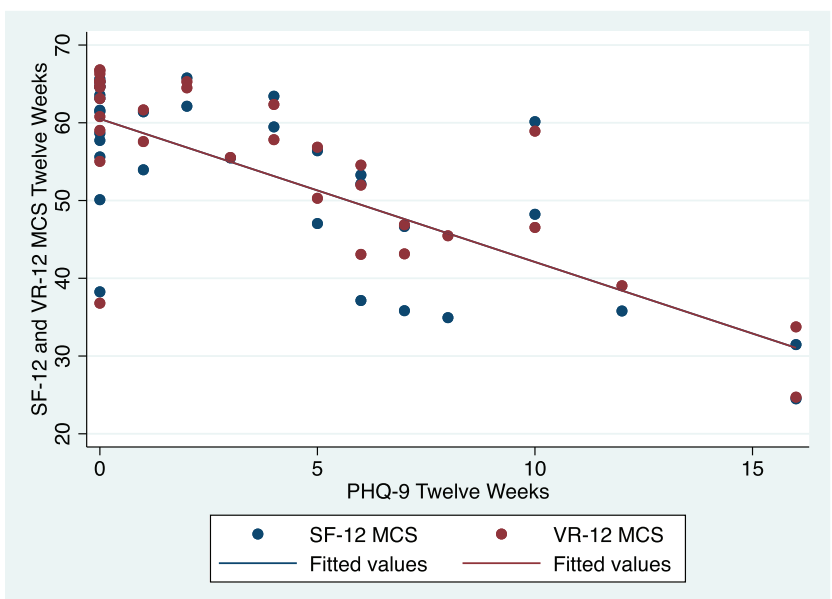

Figure 4. Patient Health Questionnaire-9 (PHQ-9) correlation scatterplot with Short Form-12 (SF-12) and Veterans RAND-12 (VR-12 MCS) at the 12-week timepoint.

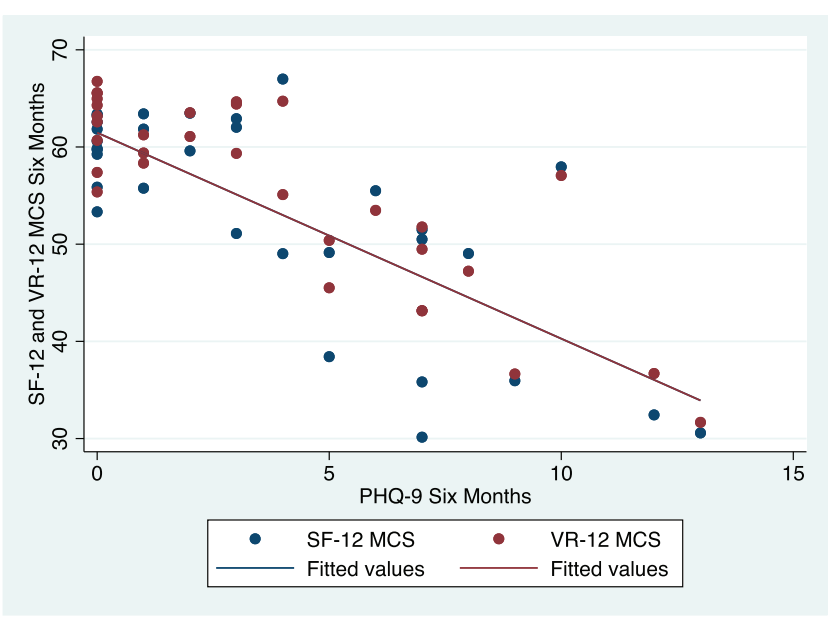

Figure 5. Patient Health Questionnaire-9 (PHQ-9) correlation scatterplot with Short Form-12 (SF-12) and Veterans RAND-12 (VR-12 MCS) at the 6-month time point.

ly invasive spine surgery has been reported to have similar or improved outcomes compared with inpatient surgery. ${ }^{60-62}$ One aspect that clinicians should consider is the impact that reduced postoperative observation can have on patients with increased anxiety and depression. Whereas some patients may prefer to recover at home, others may also be fearful of discharge from the medical care setting. Understanding that the risk for such symptoms may equally apply to patients of either gender not only underscores the need to appropriately identify and counsel such patients, but it also further highlights the importance for identifying and addressing the true root associations of lower preoperative mental health scores.

Although multiple studies indicate that addressing presurgical depressive symptoms could prevent potentially harmful influences on postsurgical outcomes, modifying preoperative depressive symptoms can be challenging and expensive, and not all interventions have been successful. Cognitive behavioral therapy interventions have demonstrated promising initial results in modifying preoperative depressive symptoms and in optimizing postoperative outcomes. ${ }^{63-65}$ In an effort to reduce costs, other automated therapies have been developed. For example, one Web-based intervention attempted to mitigate symptoms of anxiety and depression, though this model demonstrated little improvement in comparison with the control group. ${ }^{66}$ Furthermore, patients with preexisting depression diagnoses have demonstrated increased rates of other postoperative diagnoses such as anxiety, posttraumatic stress disorder, ${ }^{67}$ catastrophizing behaviors, ${ }^{68}$ de- 


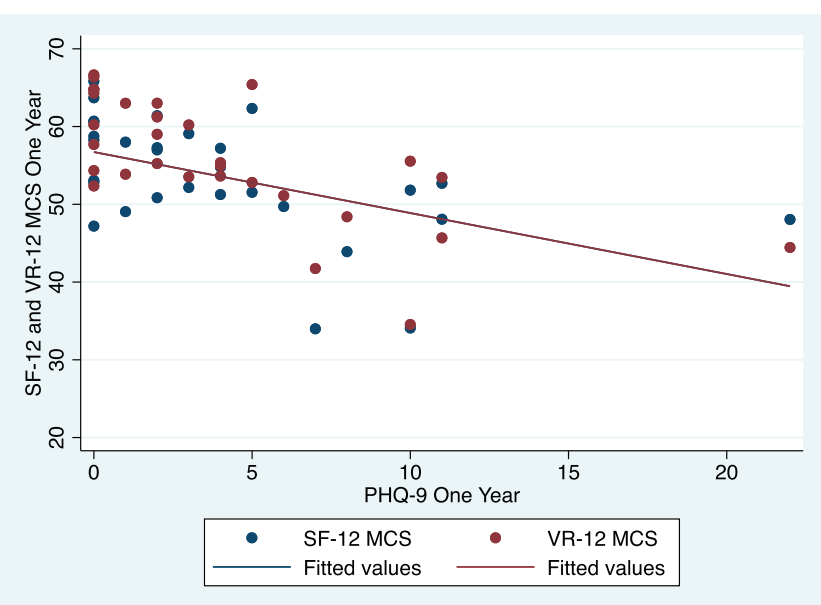

Figure 6. Patient Health Questionnaire-9 (PHQ-9) correlation scatterplot with Short Form-12 (SF-12) and Veterans RAND-12 (VR-12 MCS) at the 1-year time point.

pressive symptoms, ${ }^{52}$ and worsened mental health scores. Identifying such patients and appropriately mitigating these risk factors (in patients who are open to multidisciplinary treatment) could minimize the likelihood of patients experiencing these factors during the postoperative recovery.

Whereas the presurgical setting is an ideal place to focus counseling, identifying, and addressing mental health concerns for both genders, clinicians should also acknowledge the relevance of postoperative screening. One recent study of elective surgery patients revealed that preoperative psychological symptoms often surfaced due to concern about social support, fear regarding the operation, concern of accidental harm from clinical staff, the possibility of a blood transfusion, and being unable to recover. ${ }^{69}$ Targeting these preoperative psychosocial concerns likely entails discussing these specific issues with health care providers prior to undergoing procedures. As previously mentioned, other general categories such as the presence of pain, the need for more information, disability, employment, and psychological disturbances have all been identified and associated with both preoperative and postoperative depression. Because these factors may exist in the postoperative environment, they serve to further emphasize the importance of identifying depression susceptible patients of either gender. Whereas these factors may exist in the preoperative environment alone, the increased level of anxiety or stress in the perioperative period may unmask previously concealed depressive symptoms.
Table 5. Overall association of PHQ-9 with SF-12 MCS and VR-12 MCS.

\begin{tabular}{lccr}
\hline & \multicolumn{1}{c}{ Correlation Strength } & $\boldsymbol{P}$ Value $^{\mathbf{a}}$ \\
\hline PHQ-9 vs SF-12 MCS & & & \\
Preoperative & $-\mathbf{0 . 7 8 4}$ & Strong & $<.001$ \\
6 wk & $-\mathbf{0 . 6 9 2}$ & Strong & $<.001$ \\
$12 \mathrm{wk}$ & $-\mathbf{0 . 7 4 6}$ & Strong & $<.001$ \\
6 mo & $-\mathbf{0 . 7 5 5}$ & Strong & $<.001$ \\
1 y & $-\mathbf{0 . 5 1 3}$ & Strong & $\mathbf{. 0 0 4}$ \\
PHQ-9 vs VR-12 MCS & & & \\
Preoperative & $-\mathbf{0 . 8 7 0}$ & Strong & $<.001$ \\
6 wk & $-\mathbf{0 . 7 0 5}$ & Strong & $<.001$ \\
$12 \mathrm{wk}$ & $-\mathbf{0 . 7 9 5}$ & Strong & $<.001$ \\
6 mo & $-\mathbf{0 . 8 4 7}$ & Strong & $<.001$ \\
1 y & $-\mathbf{0 . 6 6 9}$ & Strong & $<.001$ \\
\hline
\end{tabular}

Abbreviations: MCS, mental composite scale; PHQ-9, 9-item Patient Health Questionnaire; SF-12, 12-Item Short Form; VR-12, 12-Item Veterans RAND. ${ }^{a} P$ value was calculated using PHQ-9 score at the corresponding time point, as identified by Pearson correlation coefficient $(|r| \geq .5, P<.05)$. Boldface indicates statistical significance.

\section{Limitations}

This study is not without limitations. Despite the advantage that scoring systems may have in removing human-imparted diagnostic biases, scoring systems are limited in that they are not diagnostic of depression. Hence, whereas patients with poor mental health scores may be at higher risk for experiencing the consequences of such scores, they must also be informed that scores are not equivalent to a psychiatric diagnosis. A further limitation of our study is that we only had the ability to assess the health records within our health system. Beyond postoperative day 3, we were not able to detail medications that may have been prescribed by other physicians during the preoperative and postoperative course. It is possible that at least some patients were under the care of additional providers in other health-record systems. In these cases, patients may have had variations in depressive symptoms that could have been influenced by other medications including narcotics, anxiolytics, or antidepressants. A final limitation of this study is the loss to follow-up experienced because PRO assessments were further from the date of surgery, which totaled 47 patients at the 1-year time point. This limitation may have been particularly influential within our moderate depressive symptom stratification, which had the lowest number of patients at 1-year follow-up. Whereas PRO evaluations, particularly in the postoperative time periods, may be influenced by selection bias, this study observed a decrease in the number of patients returning for evaluation. This likely influenced the increased standard deviation observed with successive PRO evaluation timepoints. 


\section{CONCLUSION}

The increased likelihood for women to experience depression has been well-researched cross-culturally and within the United States and has been validated through multiple studies. ${ }^{70-72}$ As observed in this study, for patients undergoing MIS TLIF, the differences between the genders in the preoperative environment are oftentimes trivial. Whereas numerous assertions still exist regarding gender differences and states of preoperative and postoperative mental health, this study's findings are aligned with several other recent studies that have observed similarities among spine surgery patients of both genders during preoperative and postoperative evaluations. ${ }^{43,44}$

\section{REFERENCES}

1. Tuck AN, Scribani MB, Grainger SD, Johns CA, Knight RQ. The 9-Item Patient Health Questionnaire (PHQ-9): an aid to assessment of patient-reported functional outcomes after spinal surgery. Spine J. 2018;18(8):1398-1405. doi:10.1016/j. spinee.2018.01.004

2. Irwin $\mathrm{ZN}$, Hilibrand $\mathrm{A}$, Gustavel $\mathrm{M}$, et al. Variation in surgical decision making for degenerative spinal disorders. Part I: lumbar spine. Spine. 2005;30(19):2208-2213. doi:10.1097/01. brs.0000181057.60012.08

3. Katz JN, Lipson SJ, Lew RA, et al. Lumbar laminectomy alone or with instrumented or noninstrumented arthrodesis in degenerative lumbar spinal stenosis. Patient selection, costs, and surgical outcomes. Spine. 1997;22(10):1123-1131. doi:10. 1097/00007632-199705150-00012

4. Deyo RA, Mirza SK, Martin BI. Error in trends, major medical complications, and charges associated with surgery for lumbar spinal stenosis in older adults. JAMA. 2011;306(10):1088. doi:10.1001/jama.2011.1300

5. Ciol MA, Deyo RA, Howell E, Kreif S. An assessment of surgery for spinal stenosis: time trends, geographic variations, complications, and reoperations. $J$ Am Geriatr Soc. 1996;44(3):285-290. doi:10.1111/j.1532-5415.1996.tb00915.x

6. Ibrahim T, Tleyjeh IM, Gabbar O. Surgical versus nonsurgical treatment of chronic low back pain: a meta-analysis of randomised trials. Int Orthop. 2009;33(2):589-590. doi:10.1007/ s00264-008-0665-1

7. Sherman J, Cauthen J, Schoenberg D, Burns M, Reaven NL, Griffith SL. Economic impact of improving outcomes of lumbar discectomy. Spine J. 2010;10(2):108-116. doi:10.1016/j. spinee.2009.08.453

8. Arts MP, Kols NI, Onderwater SM, Peul WC. Clinical outcome of instrumented fusion for the treatment of failed back surgery syndrome: a case series of 100 patients. Acta Neurochir. 2012;154(7):1213-1217. doi:10.1007/s00701-012-1380-7

9. Falavigna A, Righesso O, Teles AR, et al. Depression Subscale of the Hospital Anxiety and Depression Scale applied preoperatively in spinal surgery. Arq Neuropsiquiatr. 2012;70(5):352-356. doi:10.1590/s0004-282x2012000500009

10. Strøm J, Bjerrum MB, Nielsen CV, et al. Anxiety and depression in spine surgery - a systematic integrative review. Spine J. 2018;18(7):1272-1285. doi:10.1016/j.spinee.2018.03.017

11. Moore JE. Chronic low back pain and psychosocial issues. Phys Med Rehabil Clin N Am. 2010;21(4):801-815. doi:10.1016/j.pmr.2010.06.005

12. Waxman SE, Tripp DA, Flamenbaum R. The mediating role of depression and negative partner responses in chronic low back pain and relationship satisfaction. J Pain. 2008;9(5):434442. doi:10.1016/j.jpain.2007.12.007

13. Celestin J, Edwards RR, Jamison RN. Pretreatment psychosocial variables as predictors of outcomes following lumbar surgery and spinal cord stimulation: a systematic review and literature synthesis. Pain Med. 2009;10(4):639-653. doi:10. 1111/j.1526-4637.2009.00632.x

14. Abbott AD, Tyni-Lenné R, Hedlund R. Leg pain and psychological variables predict outcome 2-3 years after lumbar fusion surgery. Eur Spine J. 2011;20(10):1626-1634. doi:10. 1007/s00586-011-1709-6

15. Trief PM, Ploutz-Snyder R, Fredrickson BE. Emotional health predicts pain and function after fusion: a prospective multicenter study. Spine. 2006;31(7):823-830. doi:10.1097/01. brs.0000206362.03950.5b

16. Sinikallio S, Aalto T, Airaksinen O, Herno A, Kröger H, Viinamäki H. Depressive burden in the preoperative and early recovery phase predicts poorer surgery outcome among lumbar spinal stenosis patients: a one-year prospective follow-up study. Spine. 2009;34(23):2573-2578. doi:10.1097/BRS. 0b013e3181b317bd

17. Mannion AF, Elfering A, Staerkle R, et al. Predictors of multidimensional outcome after spinal surgery. Eur Spine J. 2007;16(6):777-786. doi:10.1007/s00586-006-0255-0

18. Davis RE, Vincent C, Henley A, McGregor A. Exploring the care experience of patients undergoing spinal surgery: a qualitative study. J Eval Clin Pract. 2013;19(1):132-138. doi:10. 1111/j.1365-2753.2011.01783.x

19. Abyholm AS, Hjortdahl P. The pain takes hold of life. A qualitative study of how patients with chronic back pain experience and cope with their life situation. Tidsskr Nor Laegeforen. 1999;119(11):1624-1629. https://europepmc.org/ abstract $/ \mathrm{med} / 10385806$

20. Abyholm AS, Hjortdahl P. Being believed is what counts. A qualitative study of experiences with the health service among patients with chronic back pain. Tidsskr Nor Laegeforen. 1999;119(11):1630-1632. https://europepmc.org/ abstract/med/10385807

21. Adogwa O, Parker SL, Shau DN, et al. Preoperative Zung Depression Scale predicts outcome after revision lumbar surgery for adjacent segment disease, recurrent stenosis, and pseudarthrosis. Spine J. 2012;12(3):179-185. doi:10.1016/j. spinee.2011.08.014

22. Chaichana KL, Mukherjee D, Adogwa O, Cheng JS, McGirt MJ. Correlation of preoperative depression and somatic perception scales with postoperative disability and quality of life after lumbar discectomy. J Neurosurg Spine. 2011;14(2):261-267. doi:10.3171/2010.10.spine 10190

23. Trief PM, Grant W, Fredrickson B. A prospective study of psychological predictors of lumbar surgery outcome. Spine. 2000;25(20):2616-2621. doi:10.1097/00007632-20001015000012

24. Hinrichs-Rocker A, Schulz K, Järvinen I, Lefering R, Simanski C, Neugebauer EAM. Psychosocial predictors and correlates for chronic post-surgical pain (CPSP) - a systematic 
review. Eur J Pain. 2009;13(7):719-730. https://onlinelibrary. wiley.com/doi/abs/10.1016/j.ejpain.2008.07.015?casa_ token=TZBKtk9_O3kAAAAA:ExlyaLIGYReqmT $\overline{3}$ c c n c m m k h 8 b Z H 0 k i w K X r k y 0 e v c p H Z G 9 i4xnnNu5q4DVH4aS_qjNPMEnF9ZePbX40. Accessed December 27, 2020.

25. Sinikallio S, Aalto T, Airaksinen O, et al. Depression is associated with poorer outcome of lumbar spinal stenosis surgery. Eur Spine J. 2007;16(7):905-912. doi:10.1007/s00586007-0349-3

26. Adogwa O, Parker SL, Shau DN, et al. Preoperative Zung Depression Scale predicts patient satisfaction independent of the extent of improvement after revision lumbar surgery. Spine J. 2013;13(5):501-506. doi:10.1016/j.spinee.2013.01.017

27. Kroenke K, Spitzer RL, Williams JB. The PHQ-9: validity of a brief depression severity measure. J Gen Intern Med. 2001;16(9):606-613. doi:10.1046/j.1525-1497.2001. 016009606.x

28. Albert PR. Why is depression more prevalent in women? J Psychiatry Neurosci. 2015;40(4):219-221. https://www.ncbi. nlm.nih.gov/pubmed/26107348. Accessed December 27, 2020.

29. Cevik B. The evaluation of anxiety levels and determinant factors in preoperative patients. Int J Med Res Health. 2018;7(1):135-143. http://www.indianjournals.com/ijor. aspx?target $=$ ijor:ijmrhs\&volume $=7 \&$ issue $=1 \&$ article $=019$.

30. Spitzer RL, Kroenke K, Williams JBW; Patient Health Questionnaire Primary Care Study Group. Validation and utility of a self-report version of PRIME-MD: the PHQ Primary Care Study. JAMA. 1999;282(18):1737-1744. doi:10. 1001/jama.282.18.1737

31. Ware J Jr, Kosinski M, Keller SD. A 12-item short-form health survey: construction of scales and preliminary tests of reliability and validity. Med Care. 1996;34(3):220-233. doi:10. 1097/00005650-199603000-00003

32. Selim AJ, Rogers W, Fleishman JA, et al. Updated US population standard for the Veterans RAND 12-item Health Survey (VR-12). Qual Life Res. 2009;18(1):43-52. doi:10.1007/ s11136-008-9418-2

33. Muller K, Cohen J. Statistical power analysis for the behavioral sciences. Technometrics. 1989;31(4):499. doi:10. $2307 / 1270020$

34. Cherkin DC, Deyo RA, Loeser JD, Bush T, Waddell G. An international comparison of back surgery rates. Spine. 1994;19(11):1201-1206. doi:10.1097/00007632-19940531000001

35. Weiss AJ, Elixhauser A, Andrews RM. Characteristics of operating room procedures in US hospitals, 2011. Rockville, MD: Agency for Healthcare Research and Quality; 2006. Healthcare Cost and Utilization Project (HCUP) Statistical Briefs No. 170.

36. Kim S, Mortaz S, Coyte P, Raja Rampersaud Y. Costutility of lumbar decompression with or without fusion for patients with symptomatic degenerative lumbar spondylolisthesis. Spine J. 2011;11(10):S26-S27. doi:10.1016/j.spinee.2011.08. 075

37. Goz V, Rane A, Abtahi AM, Lawrence BD, Brodke DS, Spiker WR. Geographic variations in the cost of spine surgery. Spine. 2015;40(17):1380-1389. doi:10.1097/BRS. 0000000000001022

38. Cram P, Landon BE, Matelski J, et al. Utilization and outcomes for spine surgery in the United States and Canada.
Spine. 2019;44(19):1371-1380. doi:10.1097/BRS. 0000000000003083

39. Weinberger AH, Gbedemah M, Martinez AM, Nash D, Galea S, Goodwin RD. Trends in depression prevalence in the USA from 2005 to 2015: widening disparities in vulnerable groups. Psychol Med. 2018;48(8):1308-1315. doi:10.1017/ S0033291717002781

40. Siccoli A, Staartjes VE, de Wispelaere MP, Schröder ML. Gender differences in degenerative spine surgery: do female patients really fare worse? Eur Spine $J$. 2018;27(10):2427-2435. doi:10.1007/s00586-018-5737-3

41. Fan G, Fu Q, Zhang J, et al. Radiation reduction of minimally invasive transforaminal lumbar interbody fusion with localisation system in overweight patients: practical technique. Bone Joint J. 2017;99-B(7):944-950. doi:10.1302/ 0301-620X.99B7.BJJ-2016-0853.R1

42. Park P, Upadhyaya C, Garton HJL, Foley KT. The impact of minimally invasive spine surgery on perioperative complications in overweight or obese patients. Neurosurgery. 2008;62(3):693-699, discussion 696-697. doi:10.1227/01.neu. $0000317318.33365 . \mathrm{f} 1$

43. Nilsson U, Berg K, Unosson M, Brudin L, Idvall E. Relation between personality and quality of postoperative recovery in day surgery patients. Eur $J$ Anaesthesiol. 2009;26(8):671-675. doi:10.1097/EJA.0b013e32832a9845

44. Jaensson M, Dahlberg K, Nilsson U. Sex similarities in postoperative recovery and health care contacts within 14 days with mHealth follow-up: secondary analysis of a randomized controlled trial. JMIR Periop Med. 2018;1(1):e2. doi:10.2196/ periop. 9874

45. Tylee A, Gastpar M, Lépine J-P, Mendlewicz J. Identification of depressed patient types in the community and their treatment needs: findings from the DEPRES II (Depression Research in European Society II) Survey. Int Clin Psychopharmacol. 1999;14:153-165. doi:10.1097/00004850199905002-00002

46. Angst J, Gamma A, Gastpar M, et al. Gender differences in depression. Epidemiological findings from the European DEPRES I and II studies. Eur Arch Psychiatry Clin Neurosci. 2002;252(5):201-209. doi:10.1007/s00406-002-0381-6

47. Thompson AH, Bland RC. Gender similarities in somatic depression and in DSM depression secondary symptom profiles within the context of severity and bereavement. J Affect Disord. 2018;227:770-776. doi:10.1016/j.jad.2017.11.052

48. Magovcevic M, Addis ME. The Masculine Depression Scale: development and psychometric evaluation. Psychol Men Masc. 2008;9(3):117-132. doi:10.1037/1524-9220.9.3.117

49. Addis ME, Mahalik JR. Men, masculinity, and the contexts of help seeking. Am Psychol. 2003;58(1):5-14. doi:10. 1037/0003-066x.58.1.5

50. Bekeris J, Wilson LA, Fiasconaro M, et al. New onset depression and anxiety after spinal fusion surgery: incidence and risk factors. Spine. March 2020;45(16):1161-1169 doi:10. 1097/BRS.0000000000003467

51. Call JB, Shafer K. Gendered manifestations of depression and help seeking among men. Am J Mens Health. 2018;12(1):41-51. doi:10.1177/1557988315623993

52. Power JD, Kudesia P, Nadeem A, et al. Patterns of depressive symptoms before and after surgery for osteoarthritis: a descriptive study. ACR Open Rheumatol. 2019;1(4):203-212. doi:10.1002/acr2.1031

53. Merrill RK, Zebala LP, Peters C, Qureshi SA, McAnany 
SJ. Impact of depression on patient-reported outcome measures after lumbar spine decompression. Spine. 2018;43(6):434-439. doi:10.1097/BRS.0000000000002329

54. Hyde JS. Gender similarities and differences. Annu Rev Psychol. 2014;65:373-398. doi:10.1146/annurev-psych-010213115057

55. O’Connell C, Azad TD, Mittal V, et al. Preoperative depression, lumbar fusion, and opioid use: an assessment of postoperative prescription, quality, and economic outcomes. Neurosurg Focus. 2018;44(1):E5. doi:10.3171/2017.10. FOCUS17563

56. Takagi H, Ando T, Umemoto T; ALICE (All-Literature Investigation of Cardiovascular Evidence) Group. Perioperative depression or anxiety and postoperative mortality in cardiac surgery: a systematic review and meta-analysis. Heart Vessels. 2017;32(12):1458-1468. doi:10.1007/s00380-017-1022-3

57. Dunn LK, Durieux ME, Fernández LG, et al. Influence of catastrophizing, anxiety, and depression on in-hospital opioid consumption, pain, and quality of recovery after adult spine surgery. J Neurosurg Spine. 2018;28(1):119-126. doi:10. 3171/2017.5.SPINE1734

58. Armaghani SJ, Lee DS, Bible JE, et al. Preoperative opioid use and its association with perioperative opioid demand and postoperative opioid independence in patients undergoing spine surgery. Spine. 2014;39(25):E1524-E1530. doi:10.1097/ BRS.0000000000000622

59. Patel DV, Yoo JS, Khechen B, et al. PHQ-9 score predicts postoperative outcomes following minimally invasive transforaminal lumbar interbody fusion. Clin Spine Surg. March 2019;32(10), 444-448. doi:10.1097/BSD. 0000000000000818

60. Emami A, Faloon M, Issa K, et al. Minimally invasive transforaminal lumbar interbody fusion in the outpatient setting. Orthopedics. 2016;39(6):e1218-e1222. doi:10.3928/ 01477447-20160721-04

61. Purger DA, Pendharkar AV, Ho AL, et al. Outpatient vs inpatient anterior cervical discectomy and fusion: a populationlevel analysis of outcomes and cost. Neurosurgery. 2018;82(4):454-464. doi:10.1093/neuros/nyx215

62. Sivaganesan A, Hirsch B, Phillips FM, McGirt MJ. Spine surgery in the ambulatory surgery center setting: valuebased advancement or safety liability? Neurosurgery. 2018;83(2):159-165. doi:10.1093/neuros/nyy057

63. Monticone M, Ferrante S, Teli M, et al. Management of catastrophising and kinesiophobia improves rehabilitation after fusion for lumbar spondylolisthesis and stenosis. A randomised controlled trial. Eur Spine J. 2014;1(1):87-95. doi:10.1007/ s00586-013-2889-z

64. Abbott AD, Tyni-Lenne R, Hedlund R. Early rehabilitation targeting cognition, behavior, and motor function after lumbar fusion: a randomized controlled trial. Spine. 2010;35(8):848-857. doi:10.1097/BRS.0b013e3181d1049f

65. Archer KR, Devin CJ, Vanston SW, et al. Cognitivebehavioral-based physical therapy for patients with chronic pain undergoing lumbar spine surgery: a randomized controlled trial. J Pain. 2016;17(1):76-89. doi:10.1016/j.jpain.2015.09.013

66. Strom J, Nielsen CV, Jorgensen LB, Andersen NT, Laursen M. A Web-based platform to accommodate symptoms of anxiety and depression by featuring social interaction and animated information in patients undergoing lumbar spine fusion: a randomized clinical trial. Spine J. 2018. doi:10.1016/j. spinee.2018.11.011

67. Anderson JT, Haas AR, Percy R, Woods ST, Ahn UM, Ahn NU. Clinical depression is a strong predictor of poor lumbar fusion outcomes among workers' compensation subjects. Spine. 2015;40(10):748-756. doi:10.1097/BRS. 0000000000000863

68. de Groot KI, de Groot KI, Boeke S, Duivenvoorden HJ, Bonke B, Passchier J. Different aspects of anxiety as predictors of post-operative anxiety and physical complaints. Pers Individ Diff. 1996;21(6):929-936. doi:10.1016/s0191-8869(96)00138-9

69. Bedaso A, Ayalew M. Preoperative anxiety among adult patients undergoing elective surgery: a prospective survey at a general hospital in Ethiopia. Patient Saf Surg. 2019;13:18. doi:10.1186/s13037-019-0198-0

70. Moieni M, Irwin MR, Jevtic I, Olmstead R, Breen EC, Eisenberger NI. Sex differences in depressive and socioemotional responses to an inflammatory challenge: implications for sex differences in depression. Neuropsychopharmacology. 2015;40(7):1709-1716. doi:10.1038/npp.2015.17

71. Pedersen CB, Mors O, Bertelsen A, et al. A comprehensive nationwide study of the incidence rate and lifetime risk for treated mental disorders. JAMA Psychiatry. 2014;71(5):573581. doi:10.1001/jamapsychiatry.2014.16

72. Malhi GS, Mann JJ. Depression. Lancet. 2018;392(10161):2299-2312. doi:10.1016/S0140-6736(18)319482

Disclosures and COI: The authors received no funding for this study and have no conflicts of interest.

Corresponding Author: Kern Singh, MD, Department of Orthopaedic Surgery, Rush University Medical Center, 1611 West Harrison St, Suite 300, Chicago, IL 60612. Phone: (312) 432-2373; Fax: (708) 409-5179; Email: kern.singh@rushortho. com.

Published 26 February 2021

This manuscript is generously published free of charge by ISASS, the International Society for the Advancement of Spine Surgery. Copyright (c) 2021 ISASS. To see more or order reprints or permissions, see http://ijssurgery.com. 